\title{
Comparison of quality characteristics of 'Makgeolli' made using brown and white rice of 'Mirchal'
}

\author{
Gi-Un Seong, Ju-Won Kang, Soo-Min Cho, Sais-Beul Lee, Jun-Hyeon Cho, Dong-Soo Park, \\ Young-Ho Kwon, So-Myeong Lee, Ji-Yoon Lee* \\ Department of Southern Area Crop Science, National Institute of Crop Science, \\ Rural Development Administration, Miryang 50424, Korea
}

\section{미르찰 현미와 백미를 이용하여 제조한 막걸리의 품질 특성 비교}

\author{
성기운 · 강주원 · 조수민 · 이샛별 · 조준현 · 박동수 · 권영호 · 이소명 · 이지윤* \\ 농촌진흥청 국립식량과학원 남부작물부
}

\begin{abstract}
In this study, we fermented 'Makgeolli' prepared using brown or white rice from 'Mirchal' for seven days to investigate the differences in their quality characteristics. Moreover, the physicochemical characteristics and antioxidant activities of 'Makgeolli' were assessed using principal component analysis (PCA). From the second day of fermentation, brown rice 'Makgeolli' exhibited a higher alcohol content $(\mathbf{7 . 0 0 \%})$ than that of white rice 'Makgeolli' $(3.60 \%)$. Additionally, the total polyphenol contents and antioxidant activities increased with the duration of fermentation $(p<0.05)$ and were higher in brown rice 'Makgeolli' than those in white rice 'Makgeolli'. Moreover, the proportion of glucose in the total free sugar content in brown rice 'Makgeolli' was 0.88 , which was higher than that in the total free sugar content in white rice 'Makgeolli' (0.60). However, the levels of soluble solids, sugars, reducing sugars, and free sugars were higher in white rice 'Makgeolli' than those in brown rice 'Makgeolli'. The PCA revealed that the quality characteristics of 'Makgeolli' prepared using brown or white rice were very distinct. Furthermore, the main contributing factor to these differences was the free sugar content. Moreover, the quality characteristics during fermentation were affected by the total acidity, polyphenol content, and alcohol content. This study provides useful data for processing 'Makgeolli' prepared using brown or white rice from 'Mirchal'.
\end{abstract}

Keywords : 'Mirchal', 'Makgeolli', rice, principal component analysis, free sugar

\section{서 론}

세계 3대 식량 작물 중 하나인 쌀은 중국, 인도 등 아시아 에서 약 $90 \%$ 이상 재배되고 있으며, 그중 세계인구 약 $40 \%$ 이상이 주식으로 하는 매우 중요한 식량 자원이다 $(\mathrm{Oh}$ 등, 2016). 우리나라에서도 벼는 주곡 작물로 중요한 위치를 차 지하고 있다. 다양한 먹을거리와 식습관 변화 등으로 현재 1 인당 연간 쌀 소비량은 2011년 $71.2 \mathrm{~kg}$ 에서 2019년 $59.2 \mathrm{~kg}$
으로 약 $16.9 \%$ 감소하였으나, 즉석밥, 양조용 등 가공용 쌀 수요는 점차 증가하고 있다(Kim과 Baek 2020). 특히 쌀 막걸 리는 쌀이 부족하던 시절의 금제에서 벗어나 다양한 제품이 유통되고 있으며, 최근 막걸리의 기능성이 부각되어 몸에 좋 은 주류로 인식되면서 그 생산과 소비량은 매년 큰 폭으로 성장하고 있다(Bae 등, 2017). 쌀 막걸리는 국내뿐만 아니라 일본, 미국, 중국 및 동남아시아 등 해외에서도 도수가 낮은 고급 주류로 분류되어 수출이 증가하고 있다.

*Corresponding author. E-mail : minitia@korea.kr, Phone : +82-55-350-1164, Fax : +82-55-352-3059

Received 23 June 2021; Revised 22 July 2021; Accepted 30 July 2021.

Copyright (c) The Korean Society of Food Preservation.

This is an Open Access article distributed under the terms of the Creative Commons Attribution Non-Commercial License (http://creativecommons.org/licenses/by-nc/4.0) which permits unrestricted non-commercial use, distribution, and reproduction in any medium, provided the original work is properly cited. 
식품공전에서 막걸리는 발아 곡류를 제외한 전분질 원료 와 국(棶) 및 물을 주된 원료로 하여 술덧을 혼탁하게 제성한 것 또는 그 발효 및 제성 과정에 탄산가스 등을 첨가한 것이 라고 명시되어 있다. 국내 대부분의 막걸리는 당화와 발효가 동시에 진행되는 방법으로 미생물이 번식된 누룩과 효모를 첨가하여 발효시켜 제조하는 병행복발효 방식으로 만들어지 며, 다양한 영양성분과 함께 생리활성물질을 함유하고 있어 기능성 품종에 따른 식이섬유 및 알코올 함량의 증대, 당 함 량 등의 품질 특성의 향상을 보인다(Lee와 Eun, 2008). 막걸 리는 원료 곡물의 종류 및 발효조건 등에 따라 품질의 차이를 나타내며, 당질, 비타민 B군 및 단백질을 함유하고 있고, 누 룩의 protease에 의한 다양한 종류의 유리아미노산을 생성하 여 막걸리의 향과 맛에 영향을 주며(Song 등, 2020), 특히 쌀 과 찹쌀 등 전분질 재료를 원료로 한 막걸리의 향기 성분으로 는 ethyl alcohol, ethyl acetate, amyl acetate 및 ethyl caproate 등이 존재한다고 보고되었다(Kim 등, 2017; Lee 등, 2012b). 또한, 발효과정 중 생성되는 lactic acid, citric acid, succinic acid, tartaric acid, pyruvic acid, malic acid 및 oxalic acid 등의 유기산은 막걸리 고유의 신선함을 부여하며, 특유의 맛과 향을 형성한다(Bang 등, 2016). 막걸리 속 항산 화 성분은 4-hydroxybenzaldehyde, 2-(4-hydroxylphenyl) ethanol (tyrosol), trans-ferulic acid, cis-ferulic acid 및 1- $H$-indole3-ethanol(tryptophol) 등으로 규명되었으며, 막걸리의 침전물 에 암세포의 억제 및 사멸을 유도하는 E,E-farnesol 성분이 다량 함유되어 항암 효과가 있는 것으로 보고되어 있다(Ha 등, 2014; Wang 등, 2012).

현재 쌀 품종을 이용한 막걸리의 품질 특성 연구로는 전분 조성이 다양한 벼 품종별 막걸리 품질 특성(Lee 등, 2013), 쌀 품종을 달리한 입국의 제조 및 막걸리의 품질 특성(Kwon 등, 2013), 고식이섬유 쌀 품종을 이용한 막걸리의 품질 특성 (Kwak 등, 2014) 및 쌀의 품종, 쌀의 도정도, 누룩에 따른 막걸리의 품질 특성(Lee 등, 2012b) 등이 보고되었다. 벼 품 종은 일반계와 통일형으로 구분할 수 있는데, 지금까지 통일 형 찰벼를 이용한 막걸리의 특성을 분석한 연구는 보고된 바 가 없다. 특히 통일형 찰벼인 미르찰은 쌀수량이 $739 \mathrm{~kg} / 10 \mathrm{a}$ 로 수량이 많고 재배안성이 높아 찹쌀을 이용하는 쌀 가공품 의 원료곡으로 사용하기 적합한 품종이다. 따라서, 본 연구에 서는 통일형 다수성 찰벼인 미르찰 현미 및 백미를 이용하여 발효기간에 따른 막걸리의 품질 특성을 비교 분석함으로써 미르찰 막걸리의 가공적 특성을 개선하고자 진행하였다.

\section{재료 및 방법}

\section{실험 재료}

본 연구에 사용된 시료는 농촌진흥청 국립식량과학원에서
개발된 통일형 초다수성 찰벼인 '미르찰’을 사용하였다. 본 연구재료는 경남 밀양시에 소재하는 농촌진흥청 국립식량과 학원 남부작물부 시험포장에서 농촌진흥청 2020년 표준재배 법에 의하여 생산되었다. 수확한 정조는 임펠라식 현미기 (FC2K, Yamamoto)로 왕겨를 제거하여 현미 시료를 준비하 였고, 현미 시료 중 일부를 사용하여 마찰식 정미기(VP-32, Yamamoto, Yamagata, Japan)로 시중 백미와 동일한 12분도 로 도정하여 백미 시료로 사용하였다. 발효제인 입국은 탁주 제조용으로 성광주조에서 성광입국(SK Brewing, Gongju, Korea), 누룩은 진주곡자에서 우리밀로 제조한 앉은뱅이 밀 누룩(Jinjugokja, Jinju, Korea), 효모는 건조된 Saccharomyces cerevisiae(La Parisienne, Marcq en Baroeul, France)를 구입 하여 실험에 사용하였다.

\section{막걸리 제조}

미르찰 현미와 백미 막걸리 제조를 위하여 각 $1 \mathrm{~kg}$ 씩 나누 어 3 회 물로 씻은 후 1 시간 수침하였다. 이후 침지한 쌀을 총 1 시간 증자하였으며, 증자 도중 30 분에 뒤집어 주었고, 상 온에서 식힌 후 고두밥을 만들었다. 막걸리 제조는 발효조에 고두밥, 입국(200 g), 누룩 $(10 \mathrm{~g})$ 및 효모(1.25 g)를 혼합한 후 $25^{\circ} \mathrm{C}$ 에서 7 일 동안 발효를 진행하였다. 발효기간 중 경시 적 변화를 관찰하기 위하여 1 일 간격으로 발효 중인 술덧을 채취하여 착즙 후 분석용 시료로 하였다.

\section{$\mathrm{pH}$, 총산, 알코올 함량 및 가용성 고형분 측정}

$\mathrm{pH}$ 는 $\mathrm{pH}$ meter(Orion 3 star, Thermoelectron Co., Beverly, $\mathrm{CA}, \mathrm{USA}$ )를 사용하여 $\mathrm{pH}$ 의 값을 측정하였다. 총산 함량은 $0.1 \mathrm{~N}$ sodium hydroxide 용액을 $\mathrm{pH} 8.35-8.40$ 이 될 때까지 중화 적정하여 초산(acetic acid) 함량(\%)으로 환산하였다. 알 코올 함량은 분석용 시료 $100 \mathrm{~mL}$ 에 증류수 $100 \mathrm{~mL}$ 를 넣어 혼합한 후 증류하였다. 증류액 $80 \mathrm{~mL}$ 를 받은 후 증류수로 $100 \mathrm{~mL}$ 로 정용하고, 증류액의 온도를 $15^{\circ} \mathrm{C}$ 로 보정한 다음 주정계(Deakwang, Seoul, Korea)를 이용하여 측정하였다. 가 용성 고형분 함량은 $\mathrm{AOAC}$ 법에 따라 $105^{\circ} \mathrm{C}$ 상압가열건조법 을 이용하여 24시간 수분을 제거한 후 항량이 될 때까지 무 게를 측정하여 백분율로 나타내었다.

\section{색도, 갈색도 및 탁도}

색도는 표준 백판 $(\mathrm{L}=97.78, \mathrm{a}=-0.39, \mathrm{~b}=2.05)$ 으로 보정한 색차계(CM-3500d, Konica Minolta, Tokyo, Japan)를 이용하 여 CIELAB값을 측정하였으며, 명도( $\mathrm{L}^{*}=$ lightness), 적색도 ( $\left.\mathrm{a}^{*}=\mathrm{redness}\right)$ 및 황색도( $\mathrm{b}^{*}=\mathrm{yellowness}$ 로 나타내었다. 갈색 도 및 탁도는 UV/VIS spectrophotometer(Softmax M5, Molecular devices, Sunnyvale, CA, USA)를 이용하여 420 
$\mathrm{nm}$ 및 $600 \mathrm{~nm}$ 에서 측정하였다.

\section{당도 및 환원당 측정}

당도는 굴절당도계(PR-201, ATAGO, Tokyo, Japan)를 사용하 여 측정하고, ${ }^{\circ} \mathrm{Brix}$ 로 표기하였다. 환원당 함량은 dinitrosalicylic $\operatorname{acid}(\mathrm{DNS})$ 에 의한 비색법으로 측정하였다(Kim 등, 1996). 분석용 시료 $1 \mathrm{~mL}$ 에 DNS 시약 $1 \mathrm{~mL}$ 를 넣고 water bath에서 10 분간 중탕한 후, 증류수 $3 \mathrm{~mL}$ 를 첨가하여 진탕한 후 UV/VIS spectrophotometer를 사용하여 $546 \mathrm{~nm}$ 에서 측정하 였다. 환원당 함량은 glucose를 사용하여 검량선의 회귀식을 이용해 $\mathrm{mg} \mathrm{GE} / 100 \mathrm{~mL}$ 로 나타내었다.

\section{유리당 분석}

유리당 함량은 분석용 시료를 $0.20 \mu \mathrm{m}$ membrane filter로 여과하여 실험에 사용하였다. HPLC(Ultimate 3000 , Termo Fisher Scientific Inc., Waltham, MS, USA)에 Column (Sugar-pack $^{\mathrm{TM}}, 6.5 \times 300 \mathrm{~mm}$, Waters, MA, USA)을 사용하 여 RI detector(214 nm, Termo Fisher Scientific Inc.)로 분석 하였다. 분석조건으로는 column temperature $80^{\circ} \mathrm{C}$, injection volume $10 \mu \mathrm{L}$, mobile phase는 distilled water를 사용하였고, flow rate는 $0.5 \mathrm{~mL} / \mathrm{min}$ 으로 분석하였다. 표준품은 raffinose, maltose, glucose, fructose(Sigma Chemical Co., St. Louis, $\mathrm{Mo}, \mathrm{USA}$ )를 사용하였고, 시료와 머무름 시간을 비교하여 검 량선의 회귀식을 이용해 $\mathrm{mg} / 100 \mathrm{~mL}$ 로 나타내었다.

\section{총페놀성 화합물 함량 및 항산화 활성 측정}

총페놀성 화합물 함량은 Folin-Ciocalteu 분석법(Singleton 과 Rossi, 1965)을 이용하여 측정하였다. 분석용 시료 0.2 $\mathrm{mL}$ 에 증류수 $1.8 \mathrm{~mL}$, Folin-Ciocalteu's phenol reagent 0.2 $\mathrm{mL}$ 를 순차적으로 혼합하여 진탕한 후, 실온에서 6분간 방치 하고, $7 \%$ sodium carbonate $2 \mathrm{~mL}$ 를 첨가한 후 UV/VIS spectrophotometer를 사용하여 $750 \mathrm{~nm}$ 에서 측정하였다. 총 페놀성 화합물 함량은 gallic acid를 사용하여 검량선의 회귀 식을 이용해 $\mathrm{mg} \mathrm{GAE} / 100 \mathrm{~mL}$ 로 나타내었다.

항산화활성은 2,2-diphenyl-1-picrylhydrazyl hydrate(DPPH) radical 소거능(Blois, 1958) 및 2,2'-azinobis-(3-ethylbenzothiazoline6-sulfonic acid)(ABTS) radical 소거능(Re 등, 1999) 분석법 으로 측정하였다. DPPH radical 소거능은 분석용 시료 $1 \mathrm{~mL}$ 에 $517 \mathrm{~nm}$ 에서 흡광도를 $1.00 \pm 0.02$ 로 조정한 $\mathrm{DPPH}$ 용액 5 $\mathrm{mL}$ 를 혼합하여 진탕한 후 암실에서 30 분간 반응시켜 517 $\mathrm{nm}$ 에서 흡광도를 측정하였다. ABTS radical 소거능은 7.4 $\mathrm{mM}$ ABTS와 $2.45 \mathrm{mM}$ potassium persulfate를 1:1(v/v)로 혼 합하여 암실에서 16시간 반응시켜 ABTS 양이온을 충분히 형성시켜 $734 \mathrm{~nm}$ 에서 흡광도 값이 $0.700 \pm 0.002$ 가 되도록 ethanol로 희석하여 ABTS solution을 만들어 실험에 사용하였 다. 분석용 시료 $0.2 \mathrm{~mL}$ 에 희석한 ABTS solution $4 \mathrm{~mL}$ 를 혼 합하여 진탕한 후 암실에서 6 분간 반응시켜 $734 \mathrm{~nm}$ 에서 흡광 도를 측정하였다. 항산화 활성은 표준물질로 Trolox를 사용하 여 검량선의 회귀식을 이용해 $\mathrm{mg} \mathrm{TE} / 100 \mathrm{~mL}$ 로 나타내었다.

\section{통계처리}

본 실험에 대한 결과값은 평균과 표준편차 $(\mathrm{Mean} \pm \mathrm{SD})$ 로 나타내었고, Statistical analysis system(9.4, SAS Institute, Cary, NC, USA)을 이용하여 one-way ANOVA 분석을 실시 한 후, Duncan's multiple range test로 발효기간에 따른 미르 찰 현미 및 백미 막걸리의 차이를 검정하였다 $(\mathrm{p}<0.05)$. 또한, 주성분 분석(principal component analysis, $\mathrm{PCA}$ )을 이용하여 품질 특성 $(\mathrm{pH}$, 총산, 알코올 함량, 가용성 고형분 함량, 당도, 환원당 함량, 유리당 함량, 총페놀성 화합물 함량, 항산화 활 성)을 측정 변수로 하고, 발효기간에 따른 미르찰 현미와 백 미 막걸리를 관측대상으로 하여 주성분(principal component, $\mathrm{PC}$ )과의 연관성을 도출하고자 하였으며, 통계처리는 SAS 9.4 를 이용하였다.

\section{결과 및 고찰}

\section{$\mathrm{pH}$, 총산, 알코올 함량 및 가용성 고형분 함량}

미르찰 현미와 백미 막걸리의 $\mathrm{pH}$, 총산, 알코올 함량 및 가용성 고형분 함량을 측정한 결과는 Table 1에 나타내었다. 미르찰 현미와 백미 막걸리의 $\mathrm{pH}$ 는 각각 현미 막걸리 4.234.47과 백미 막걸리 3.69-3.96으로 현미 막걸리의 $\mathrm{pH}$ 가 더 높았다. 발효 2 일차에서 미르찰 현미와 백미 막걸리의 $\mathrm{pH}$ 는 각각 현미 막걸리 4.23과 백미 막걸리 3.69로 유의적으로 낮 았다. 일반적인 막걸리의 $\mathrm{pH}$ 는 4.0-4.6의 범위의 값을 나타내 는데, 본 연구에서도 유사한 값을 보여 정상적인 발효가 진행 된 것으로 사료된다(Lee와 Park, 1995). 또한, 미르찰 현미와 백미 막걸리의 $\mathrm{pH}$ 는 발효 1 일에 4.38 및 3.95의 값을 보였으 나 2 일차에 낮아지는 경향을 보였다. 하지만 발효 3 일부터는 유의적으로 증가하였으며, 이는 막걸리의 발효 진행 과정 중 $\mathrm{pH}$ 는 담금 직후를 제외한 발효과정 중의 $\mathrm{pH}$ 차이는 거의 없 는 편이라는 보고와 유사한 결과이다(Lee 등, 1996). 막걸리 의 총산은 관능적인 품질과 저장성에 영향을 주며, 발효가 진 행됨에 따라 술덧에 의한 효모 및 젖산균 등의 생화학적 작용 으로 생성된 유기산에 의해 증가된다. 총산이 지나치게 높은 경우, 알코올 발효를 넘어 초산 발효에 의해 식초가 형성되어 막걸리의 전반적인 품질에 영향을 준다고 알려져 있다 (Chung 등, 2017; Kwak 등, 2014). 미르찰 현미와 백미 막걸 리의 총산은 각각 현미 막걸리 $0.46-0.90 \%$ 와 백미 막걸리 
Table 1. pH, titratable acidity, alcohol and soluble solid contents of 'Makgeolli' made using brown and white rice of 'Mirchal'

\begin{tabular}{|c|c|c|c|c|c|c|c|c|}
\hline & \multirow{2}{*}{ Rice } & \multicolumn{7}{|c|}{ Fermentation (day) } \\
\hline & & 1 & 2 & 3 & 4 & 5 & 6 & 7 \\
\hline \multirow{2}{*}{$\mathrm{pH}$} & Brown & $4.38 \pm 0.01^{\mathrm{bc} 1)}$ & $4.23 \pm 0.03^{\mathrm{d}}$ & $4.36 \pm 0.02^{\mathrm{c}}$ & $4.36 \pm 0.01^{\mathrm{c}}$ & $4.36 \pm 0.02^{\mathrm{c}}$ & $4.41 \pm 0.02^{\mathrm{b}}$ & $4.47 \pm 0.02^{\mathrm{a}}$ \\
\hline & White & $3.95 \pm 0.02^{\mathrm{a}}$ & $3.69 \pm 0.03^{\mathrm{d}}$ & $3.74 \pm 0.08^{\mathrm{cd}}$ & $3.79 \pm 0.03^{\mathrm{bc}}$ & $3.75 \pm 0.02^{\mathrm{cd}}$ & $3.83 \pm 0.03^{\mathrm{b}}$ & $3.96 \pm 0.03^{\mathrm{a}}$ \\
\hline \multirow{2}{*}{$\begin{array}{c}\text { Total acidity } \\
(\%)\end{array}$} & Brown & $0.46 \pm 0.00^{\mathrm{e}}$ & $0.90 \pm 0.02^{\mathrm{a}}$ & $0.78 \pm 0.02^{\mathrm{c}}$ & $0.84 \pm 0.02^{\mathrm{b}}$ & $0.84 \pm 0.02^{\mathrm{b}}$ & $0.79 \pm 0.02^{\mathrm{c}}$ & $0.71 \pm 0.02^{\mathrm{d}}$ \\
\hline & White & $0.54 \pm 0.01^{\mathrm{f}}$ & $0.74 \pm 0.00^{\mathrm{d}}$ & $0.79 \pm 0.03^{\mathrm{bc}}$ & $0.88 \pm 0.04^{\mathrm{a}}$ & $0.83 \pm 0.02^{\mathrm{b}}$ & $0.78 \pm 0.02^{\text {cd }}$ & $0.69 \pm 0.02^{\mathrm{e}}$ \\
\hline \multirow{2}{*}{$\begin{array}{c}\text { Alcohol } \\
\text { content }(\%)\end{array}$} & Brown & $0.40 \pm 0.00^{\mathrm{f}}$ & $7.00 \pm 0.00^{\mathrm{e}}$ & $9.00 \pm 0.00^{\mathrm{d}}$ & $9.40 \pm 0.00^{c}$ & $11.60 \pm 0.00^{\mathrm{b}}$ & $11.60 \pm 0.00^{\mathrm{b}}$ & $11.80 \pm 0.00^{\mathrm{a}}$ \\
\hline & White & $0.40 \pm 0.00^{\mathrm{f}}$ & $3.60 \pm 0.00^{\mathrm{e}}$ & $8.00 \pm 0.00^{\mathrm{d}}$ & $8.40 \pm 0.00^{\mathrm{c}}$ & $11.60 \pm 0.00^{\mathrm{b}}$ & $12.00 \pm 0.00^{\mathrm{a}}$ & $12.00 \pm 0.00^{\mathrm{a}}$ \\
\hline \multirow{2}{*}{$\begin{array}{l}\text { Soluble solid } \\
\text { content }(\%)\end{array}$} & Brown & $13.94 \pm 0.10^{\mathrm{b}}$ & $9.20 \pm 0.07^{\mathrm{g}}$ & $11.41 \pm 0.05^{\mathrm{f}}$ & $12.12 \pm 0.01^{\mathrm{e}}$ & $12.83 \pm 0.02^{\mathrm{d}}$ & $13.79 \pm 0.00^{\mathrm{c}}$ & $14.33 \pm 0.03^{\mathrm{a}}$ \\
\hline & White & $29.75 \pm 0.06^{\mathrm{a}}$ & $26.26 \pm 0.11^{\mathrm{b}}$ & $21.10 \pm 0.10^{\mathrm{c}}$ & $18.76 \pm 0.03^{\mathrm{d}}$ & $17.46 \pm 0.05^{\mathrm{e}}$ & $17.50 \pm 0.04^{\mathrm{d}}$ & $18.01 \pm 0.07^{\mathrm{e}}$ \\
\hline
\end{tabular}

${ }^{1)}$ Mean \pm SD ( $\left.n=3\right)$ within each row followed by different letters are significantly different $(\mathrm{p}<0.05)$.

$0.54-0.88 \%$ 의 범위를 보였으며, 최종 발효단계에서는 $0.71 \%$ 와 $0.69 \%$ 를 나타내었다. Lee 등(2012b)에 따르면 알코올 함 량 $16 \%$ 의 수율을 얻은 14 종의 막걸리를 $6 \%$ 함량으로 제성 하여 총산을 분석한 결과, $0.24-0.37 \%$ 의 값을 보인다고 보고 하였다. 반면, 본 연구에서는 제성하지 않은 결과값으로, 주 세법에 따른 막걸리 제조 시 비슷한 경향을 보일 것으로 사료 된다(Lee와 Park, 1995). 미르찰 현미와 백미 막걸리의 알코 올 함량은 발효 7 일차에 현미 막걸리 $11.80 \%$ 및 백미 막걸리 $12.00 \%$ 를 나타냈다. 발효 초기에 미르찰 현미와 백미 막걸리 는 낮은 알코올 함량 $(0.40 \%)$ 을 보인 반면, 발효 2 일차에는 미 르찰 현미와 백미 막걸리의 알코올 함량은 각각 $7.00 \%$ 와 $3.60 \%$ 로 미르찰 현미 막걸리의 알코올 함량이 높았다. 3 일차 부터 미르찰 현미와 백미 막걸리의 알코올 햠량은 각각 $9.00 \%$ 와 $8.00 \%$ 이었으며, 발효 종료시점까지 유의적으로 증 가하여 유사한 경향을 보였다. 쌀 품종에 따른 막걸리의 품질 특성 보고에 의하면 알코올 함량은 11.5-14.5\%로 쌀 품종에 따른 차이가 있었으며, 추청, 일미, 온누리, 삼광 및 신동진 품종이 약 $12 \%$ 의 알코올 함량으로 본 연구결과와 유사한 함 량의 값을 보였다(Kwon 등, 2013). 미르찰 현미와 백미 막걸 리의 가용성 고형분 함량을 분석한 결과, 미르찰 백미 막걸리 (17.46-29.75\%)의 함량이 미르찰 현미 막걸리(9.20-14.33\%) 의 함량보다 높게 나타났다. Han 등(1997)에 따르면 시중에 서 판매되는 멥쌀을 이용하여 제조한 막걸리의 최종 발효단 계에서의 가용성 고형분 함량 약 $10 \%$ 와 비교하였을 때 미르 찰 현미 막걸리(14.33\%)와 백미 막걸리(18.01\%)의 가용성 고형분 함량이 높은 것으로 사료된다.

\section{색도, 갈색도 및 탁도}

미르찰 현미와 백미 막걸리의 색도, 갈색도 및 탁도를 측
정한 결과는 Table 2에 나타내었다. 미르찰 현미와 백미 막걸 리의 명도 $\left(\mathrm{L}^{*}\right)$ 는 각각 $30.22-36.12$ 와 39.17-47.45의 범위로 백미를 이용한 막걸리에서 더 높게 나타났으며, 적색도 $\left(\mathrm{a}^{*}\right)$ 는 3.97-6.23과 -0.33-2.49의 값을 보였고, 황색도 $\left(\mathrm{b}^{*}\right)$ 는 29.0633.54와 17.69-26.77로 나타났다. 미르찰 백미 막걸리는 현미 막걸리보다 $\mathrm{L} *$ 값은 높은 데 비하여 $\mathrm{a}$ *값, $\mathrm{b}$ *값이 낮게 나타 났으며, 이는 막걸리 제조에 사용되는 쌀가루의 입도가 미세 할수록 $\mathrm{L} *$ 값이 증가한다는 결과와 유사하였다(Lee 등, 2012a). 또한, 발효기간이 지남에 따라 색도의 변화가 줄어들 었으며, 저온에서 저장기간이 길어질수록 색의 변화는 감소 된다고 하였다(Kim 등, 2017). 미르찰 현미와 백미 막걸리의 발효기간에 따른 수용성 색소 및 탁한 정도를 비교하기 위하 여 갈색도 및 탁도에 대한 품질변화를 확인하였다. 갈색도는 각각 현미 막걸리 0.13-0.30과 백미 막걸리 0.18-0.34의 범위 로 나타났으며, 탁도는 각각 현미 막걸리 0.08-0.20과 백미 막걸리 0.12-0.25의 범위를 나타내었다. 갈색도와 탁도의 경 우 발효 2일차까지 백미 막걸리가 높은 값을 나타냈지만, 발 효 3일차부터는 현미 막걸리보다 낮은 값을 나타냈으며, 발효 7일차까지 그 값이 유지되었다.

\section{당도 및 환원당 함량}

미르찰 현미와 백미 막걸리의 당도 및 환원당 함량을 측정 한 결과는 Fig. 1에 나타내었다. 당도는 각각 현미 막걸리 11.80-17.40 ${ }^{\circ} \mathrm{Brix}$ 와 백미 막걸리 20.40-28.23 ${ }^{\circ} \mathrm{Brix}$ 의 범위 로 나타났으며, 백미 막걸리가 현미 막걸리보다 당도가 높게 나타났다. 발효가 진행됨에 따라 현미 막걸리는 발효 1 일차 $12.00{ }^{\circ} \mathrm{Brix}$ 에서 발효 7 일차 $17.20{ }^{\circ} \mathrm{Brix}$ 를 나타내어 당도가 유의적으로 증가하였으나, 백미 막걸리는 발효가 진행됨에 따라 발효 1 일차 $28.23{ }^{\circ} \mathrm{Brix}$ 에서 발효 7 일차 $20.50{ }^{\circ} \mathrm{Brix}$ 로 
Table 2. Hunter's color value, brown color and turbidity of 'Makgeolli' made using brown and white rice of 'Mirchal'

\begin{tabular}{|c|c|c|c|c|c|c|c|c|c|}
\hline & & \multirow{2}{*}{ Rice } & \multicolumn{7}{|c|}{ Fermentation (day) } \\
\hline & & & 1 & 2 & 3 & 4 & 5 & 6 & 7 \\
\hline \multirow{6}{*}{$\begin{array}{l}\text { Hunter's } \\
\text { color } \\
\text { value }^{1)}\end{array}$} & \multirow{2}{*}{$\mathrm{L}^{*}$} & Brown & $32.48 \pm 0.17^{\mathrm{e} 2)}$ & $30.22 \pm 0.06^{\mathrm{f}}$ & $30.28 \pm 0.02^{\mathrm{f}}$ & $34.22 \pm 0.04^{\mathrm{d}}$ & $34.36 \pm 0.02^{\mathrm{c}}$ & $36.12 \pm 0.03^{\mathrm{a}}$ & $34.66 \pm 0.02^{b}$ \\
\hline & & White & $41.72 \pm 0.01^{\mathrm{d}}$ & $47.45 \pm 0.03^{\mathrm{a}}$ & $45.34 \pm 0.02^{\mathrm{b}}$ & $43.00 \pm 0.03^{\mathrm{c}}$ & $41.61 \pm 0.02^{\mathrm{e}}$ & $40.55 \pm 0.09^{\mathrm{f}}$ & $39.17 \pm 0.04^{\mathrm{g}}$ \\
\hline & \multirow{2}{*}{$a^{*}$} & Brown & $3.97 \pm 0.04^{\mathrm{g}}$ & $6.16 \pm 0.03^{b}$ & $6.23 \pm 0.02^{\mathrm{a}}$ & $5.19 \pm 0.01^{\mathrm{e}}$ & $5.36 \pm 0.01^{\mathrm{c}}$ & $4.72 \pm 0.01^{\mathrm{f}}$ & $5.32 \pm 0.01^{\mathrm{d}}$ \\
\hline & & White & $0.71 \pm 0.01^{\mathrm{e}}$ & $-0.33 \pm 0.01^{\mathrm{g}}$ & $0.12 \pm 0.01^{\mathrm{f}}$ & $0.83 \pm 0.01^{\mathrm{d}}$ & $1.69 \pm 0.01^{\mathrm{c}}$ & $1.99 \pm 0.02^{\mathrm{b}}$ & $2.49 \pm 0.01^{\mathrm{a}}$ \\
\hline & \multirow{2}{*}{$b^{*}$} & Brown & $29.06 \pm 0.08^{\mathrm{g}}$ & $32.88 \pm 0.02^{\mathrm{b}}$ & $33.54 \pm 0.03^{\mathrm{a}}$ & $32.50 \pm 0.02^{\mathrm{e}}$ & $32.54 \pm 0.03^{\mathrm{d}}$ & $32.26 \pm 0.02^{\mathrm{f}}$ & $32.68 \pm 0.02^{\mathrm{c}}$ \\
\hline & & White & $21.87 \pm 0.01^{\mathrm{e}}$ & $17.69 \pm 0.03^{\mathrm{g}}$ & $20.55 \pm 0.02^{\mathrm{f}}$ & $22.54 \pm 0.02^{\mathrm{d}}$ & $24.60 \pm 0.02^{\mathrm{c}}$ & $25.97 \pm 0.04^{\mathrm{b}}$ & $26.77 \pm 0.03^{\mathrm{a}}$ \\
\hline \multirow{2}{*}{\multicolumn{2}{|c|}{$\begin{array}{l}\text { Brown color } \\
\text { (OD. } 420 \mathrm{~nm})\end{array}$}} & Brown & $0.13 \pm 0.00^{\mathrm{e}}$ & $0.24 \pm 0.00^{\mathrm{d}}$ & $0.27 \pm 0.00^{\mathrm{c}}$ & $0.28 \pm 0.00^{\mathrm{b}}$ & $0.28 \pm 0.00^{\mathrm{b}}$ & $0.27 \pm 0.00^{\mathrm{bc}}$ & $0.30 \pm 0.00^{\mathrm{a}}$ \\
\hline & & White & $0.28 \pm 0.00^{\mathrm{b}}$ & $0.34 \pm 0.01^{\mathrm{a}}$ & $0.24 \pm 0.00^{c}$ & $0.19 \pm 0.00^{\mathrm{e}}$ & $0.18 \pm 0.00^{\mathrm{e}}$ & $0.19 \pm 0.00^{\mathrm{e}}$ & $0.21 \pm 0.01^{\mathrm{d}}$ \\
\hline \multirow{2}{*}{\multicolumn{2}{|c|}{$\begin{array}{c}\text { Turbidity } \\
\text { (OD. } 600 \mathrm{~nm})\end{array}$}} & Brown & $0.08 \pm 0.00^{\mathrm{d}}$ & $0.17 \pm 0.00^{c}$ & $0.18 \pm 0.00^{\mathrm{b}}$ & $0.18 \pm 0.00^{\mathrm{b}}$ & $0.18 \pm 0.00^{\mathrm{b}}$ & $0.18 \pm 0.00^{\mathrm{b}}$ & $0.20 \pm 0.00^{\mathrm{a}}$ \\
\hline & & White & $0.20 \pm 0.01^{\mathrm{b}}$ & $0.25 \pm 0.00^{\mathrm{a}}$ & $0.19 \pm 0.02^{b}$ & $0.16 \pm 0.01^{\mathrm{c}}$ & $0.14 \pm 0.01^{\mathrm{d}}$ & $0.12 \pm 0.00^{\mathrm{d}}$ & $0.15 \pm 0.01^{\mathrm{c}}$ \\
\hline
\end{tabular}

${ }^{1)} \mathrm{L}^{*}$, lightness (white $+100 \leftrightarrow 0$ black); $\mathrm{a}^{*}$, redness (red $+100 \leftrightarrow 0 \leftrightarrow-80$ green); $\mathrm{b}^{*}$, yellowness (yellow $+70 \leftrightarrow 0 \leftrightarrow-80$ blue).

${ }^{2)}$ Mean $\pm \mathrm{SD}(\mathrm{n}=10)$ within each row followed by different letters are significantly different $(\mathrm{p}<0.05)$.

(A)

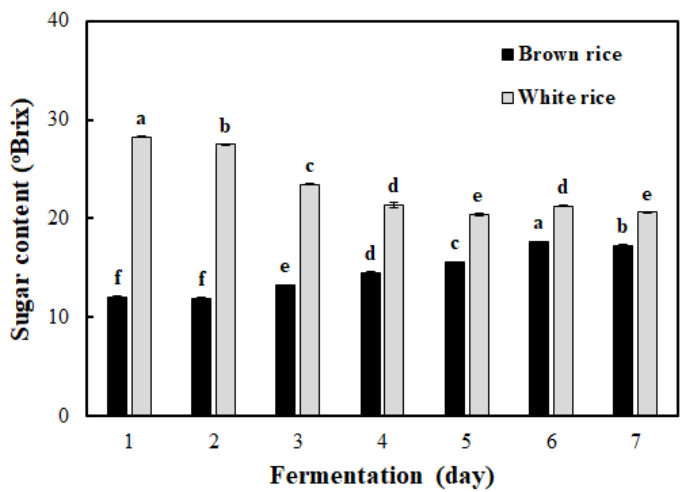

(B)

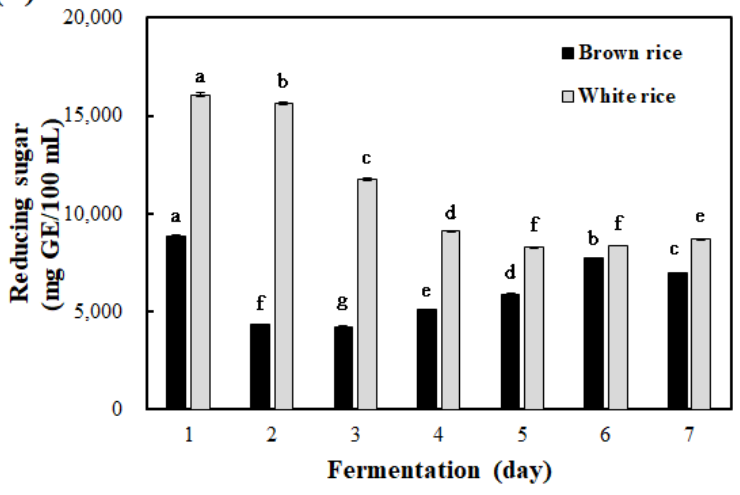

Fig. 1. Sugar content (A) and reducing sugar content (B) of 'Makgeolli' made using brown and white rice of 'Mirchal'.

Values represent the mean $\pm S D(n=3)$. Means with different letters $\left.{ }^{(-\mathrm{a} g}\right)$ above a bar are significantly different at $\mathrm{p}<0.05$.
유의적으로 감소하여 현미를 이용한 막걸리와 반대되는 경향 을 보였다. 이는 효모에 의한 알코올 발효가 급격히 진전되어 일시적으로 당의 함량이 감소된 것으로 고아미 2 호, 고아미 3 호 및 고아미4호의 백미 막걸리가 발효 2일째에 당도가 급감 되었다는 Kwak 등(2014)의 보고와 일치하는 결과이다. 환원 당 분석 결과 미르찰 현미 막걸리는 4,369-8,859 mg/100 mL 로, 백미 막걸리는 8,275-16,064 mg/100 mL의 범위를 보여 당도와 유사한 경향을 나타내었다. 환원당은 막걸리 발효과 정 중 탄수화물의 분해로 생성되고, 감미에 영향을 주는 주요 성분으로 산미와 감칠맛 등과 함께 막걸리의 관능적 품질에 영향을 미친다(Lee 등, 2013). 미르찰 현미 막걸리는 발효 2 일차에 $4,369 \mathrm{mg} / 100 \mathrm{~mL}$ 로 1 일차보다 $4,490 \mathrm{mg} / 100 \mathrm{~mL}$ 감 소하였으나, 이후 발효기간에 따라 유의적으로 증가하였다. 반 면, 미르찰 백미 막걸리의 경우 발효 1 일차에 $16,064 \mathrm{mg} / 100$ $\mathrm{mL}$ 에서 $8,680 \mathrm{mg} / 100 \mathrm{~mL}$ 로 감소하는 경향을 보였다. Park 등(2011)의 보고에 따르면 막걸리 제조 시 병행복발효 과정 에서 효소제, 발효온도, 시간 등은 환원당 생성에 영향을 주 며, 잔류당분과 생성된 알코올 함량 사이에 상호관계가 있다 고 보고하였다.

\section{유리당 함량}

미르찰 현미와 백미 막걸리의 유리당 함량을 분석한 결과 는 Table 3 에 나타내었다. 미르찰 현미와 백미 막걸리에서 raffinose, maltose, glucose 및 fructose 4 종의 유리당이 확인 되었다. 그중 glucose는 미르찰 현미와 백미 막걸리에서 각각 
Table 3. Sugar profiles (mg/100 $\mathrm{mL})$ of 'Makgeolli' made using brown and white rice of 'Mirchal'

\begin{tabular}{|c|c|c|c|c|c|c|c|c|}
\hline & \multirow{2}{*}{ Rice } & \multicolumn{7}{|c|}{ Fermentation (day) } \\
\hline & & 1 & 2 & 3 & 4 & 5 & 6 & 7 \\
\hline \multirow{2}{*}{ Raffinose } & Brown & $73.8 \pm 9.3^{\mathrm{a} 2)}$ & $60.4 \pm 5.3^{\mathrm{b}}$ & $29.3 \pm 4.6^{\mathrm{c}}$ & $26.3 \pm 2.8^{\mathrm{c}}$ & $25.9 \pm 1.6^{\mathrm{c}}$ & $33.1 \pm 1.2^{\mathrm{c}}$ & $24.9 \pm 1.8^{\mathrm{c}}$ \\
\hline & White & $478.9 \pm 57.6^{\mathrm{a}}$ & $511.5 \pm 15.3^{\mathrm{a}}$ & $376.8 \pm 52.1^{\mathrm{b}}$ & $261.5 \pm 32.6^{\mathrm{c}}$ & $246.7 \pm 24.5^{\mathrm{cd}}$ & $198.0 \pm 15.8^{\mathrm{d}}$ & $195.3 \pm 12.2^{d}$ \\
\hline \multirow{2}{*}{ Maltose } & Brown & $201.4 \pm 25.1^{\mathrm{a}}$ & $174.2 \pm 14.8^{b}$ & $83.9 \pm 3.8^{d}$ & $66.1 \pm 6.8^{d}$ & $67.1 \pm 6.7^{\mathrm{d}}$ & $107.9 \pm 9.3^{\mathrm{c}}$ & $73.4 \pm 6.1^{d}$ \\
\hline & White & $614.6 \pm 69.1^{b}$ & $726.4 \pm 17.8^{\mathrm{a}}$ & $634.1 \pm 88.5^{\mathrm{b}}$ & $471.2 \pm 54.4^{\mathrm{c}}$ & $441.0 \pm 42.7^{\mathrm{cd}}$ & $368.2 \pm 29.9^{d}$ & $377.0 \pm 21.4^{\mathrm{cc}}$ \\
\hline \multirow{2}{*}{ Glucose } & Brown & $805.0 \pm 74.7^{\mathrm{a}}$ & $333.1 \pm 32.8^{\mathrm{d}}$ & $362.6 \pm 15.3^{\mathrm{d}}$ & $505.8 \pm 41.6^{\mathrm{c}}$ & $589.8 \pm 50.9^{c}$ & $808.3 \pm 70.4^{\mathrm{a}}$ & $706.5 \pm 58.2^{\mathrm{b}}$ \\
\hline & White & $1,325 \cdot 6 \pm 121.3^{\mathrm{a}}$ & $1,352 \cdot 1 \pm 54 \cdot 1^{\mathrm{a}}$ & $1,002.6 \pm 124.0^{b}$ & $790.6 \pm 56.6^{\mathrm{c}}$ & $769.4 \pm 53.0^{\mathrm{c}}$ & $861.7 \pm 75.3^{\mathrm{bc}}$ & $869.2 \pm 48.5^{\mathrm{bc}}$ \\
\hline \multirow{2}{*}{ Frutose } & Brown & $0.5 \pm 0.0^{\mathrm{a}}$ & $\mathrm{ND}^{3)}$ & ND & ND & ND & ND & ND \\
\hline & White & ND & ND & ND & ND & ND & ND & ND \\
\hline \multirow{2}{*}{ Total } & Brown & $1,080.7 \pm 108.3^{\mathrm{a}}$ & $567.7 \pm 32.6^{\mathrm{de}}$ & $475.7 \pm 21.1^{\mathrm{e}}$ & $598.1 \pm 51.0^{\mathrm{d}}$ & $682.8 \pm 58.68^{d}$ & $949.3 \pm 79.6^{\mathrm{b}}$ & $804.8 \pm 65.4^{\mathrm{c}}$ \\
\hline & White & $2,419.1 \pm 247.8^{\mathrm{a}}$ & $2,590.0 \pm 78.5^{\mathrm{a}}$ & $2,013.5 \pm 264.6^{\mathrm{b}}$ & $1,523.2 \pm 141.0^{\mathrm{c}}$ & $1,457.1 \pm 120.3^{\mathrm{c}}$ & $1,427.9 \pm 116.4^{\mathrm{c}}$ & $1,441.5 \pm 81.7^{\mathrm{c}}$ \\
\hline \multirow{2}{*}{$\mathrm{G} / \mathrm{T}^{1)}$} & Brown & $0.75 \pm 0.01^{\mathrm{c}}$ & $0.59 \pm 0.04^{\mathrm{d}}$ & $0.76 \pm 0.01^{\mathrm{c}}$ & $0.85 \pm 0.00^{\mathrm{b}}$ & $0.86 \pm 0.00^{\mathrm{ab}}$ & $0.85 \pm 0.00^{b}$ & $0.88 \pm 0.00^{\mathrm{a}}$ \\
\hline & White & $0.55 \pm 0.01^{\mathrm{b}}$ & $0.52 \pm 0.01^{\mathrm{c}}$ & $0.50 \pm 0.00^{\mathrm{d}}$ & $0.52 \pm 0.01^{\mathrm{c}}$ & $0.53 \pm 0.01^{\mathrm{c}}$ & $0.60 \pm 0.01^{\mathrm{a}}$ & $0.60 \pm 0.00^{\mathrm{a}}$ \\
\hline
\end{tabular}

${ }^{1)}$ Ratio of glucose compared to total free sugars.

${ }^{2)}$ Mean \pm SD $(n=3)$ within each row followed by different letters are significantly different $(\mathrm{p}<0.05)$.

${ }^{3)}$ Not detected.

$333.1-808.3 \mathrm{mg} / 100 \mathrm{~mL}$ 와 $769.4-1,352.1 \mathrm{mg} / 100 \mathrm{~mL}$ 의 범 위로 유리당 함량 중 가장 높게 나타났으며, maltose(현미 막 걸리, $66.1-201.4 \mathrm{mg} / 100 \mathrm{~mL}$; 백미 막걸리, $368.2-726.4 \mathrm{mg} /$ $100 \mathrm{~mL}$ ), raffinos(현미 막걸리, 24.9-73.8 mg/100 mL; 백미 막 걸리, $195.3-511.5 \mathrm{mg} / 100 \mathrm{~mL}$ ) 순으로 확인되었다. Fructose의 경우, 미르찰 현미를 이용한 막걸리의 발효 1 일차에 $0.5 \mathrm{mg} / 100$ $\mathrm{mL}$ 가 확인되었으나, 발효 2일차부터는 검출되지 않았다. 미 르찰 현미와 백미를 이용하여 막걸리를 제조할 때 총 유리당 함량은 발효 1 일차에 각각 $1,080.7 \mathrm{mg} / 100 \mathrm{~mL}$ 와 $2,419.1$ $\mathrm{mg} / 100 \mathrm{~mL}$ 로 발효가 진행됨에 따라 감소하는 경향을 보였 다. 미르찰 현미와 백미 막걸리의 전체 유리당에 대한 glucose 의 비율 $(\mathrm{G} / \mathrm{T})$ 을 분석한 결과, 현미 막걸리의 경우 발효 1 일차 에는 $\mathrm{G} / \mathrm{T}$ 값이 0.75 , 발효 2 일차에는 0.59 로 $\mathrm{G} / \mathrm{T}$ 값이 급격 히 감소하였으나, 이후 다시 증가하여 0.88 로 나타났다. 반면, 총 유리당 함량이 높은 백미 막걸리의 경우 $\mathrm{G} / \mathrm{T}$ 값이 발효 1 일차에 0.55 로 현미보다 0.20 낮았으며 발효 7일차에는 0.60 으로 증가하였지만, 현미 막걸리와 0.28 의 차이를 보였다. 이 러한 결과로 막걸리의 주요 유리당은 glucose이며, 미르찰 현 미 막걸리가 백미 막걸리보다 전체 유리당에 대한 glucose의 비율이 높은 것을 알 수 있었다. 또한, 국내 시판막걸리 8종 에 대한 유리당 함량 중 glucose의 함량이 모두 높게 나타났 으며(Park 등, 2011), glucose의 함량은 원료의 종류 및 투입 량, 효소 종류 및 활성도, 발효 조건에 따라 유리당 함량에
차이를 나타낸다고 보고하였다(Lee 등, 1996).

\section{총페놀성 화합물 함량 및 항산화 활성}

미르찰 현미와 백미 막걸리의 총페놀성 화합물 함량 및 항 산화 활성을 분석한 결과는 Fig. 2에 나타내었다. 총페놀성 화합물 함량은 각각 미르찰 현미 막걸리 $42.00-93.37 \mathrm{mg}$ $\mathrm{GAE} / 100 \mathrm{~mL}$ 와 백미 막걸리 $36.97-76.08 \mathrm{mg} \mathrm{GAE} / 100 \mathrm{~mL}$ 의 범위로 나타났으며, 발효가 진행될수록 총페놀성 화합물 함 량이 증가하여 발효기간 중 발효 7일차에 현미 막걸리(93.37 $\mathrm{mg} \mathrm{GAE} / 100 \mathrm{~mL})$ 와 백미 막걸리(76.08 mg GAE/100 mL)가 가장 높은 함량을 각각 나타냈다 $(\mathrm{p}<0.05) . \mathrm{DPPH}$ 라디칼 소 거 활성은 미르찰 현미와 백미 막걸리에서 각각 14.91-19.95 $\mathrm{mg} \mathrm{TE} / 100 \mathrm{~mL}$ 와 5.37-7.15 mg TE/100 mL의 값을 보였으 며, ABTS 라디칼 소거활성은 현미 막걸리와 백미 막걸리 각 각 25.41-35.54 mg TE/100 mL와 6.49-15.60 mg TE/100 mL 의 범위를 나타냈다. 항산화 활성의 결과 총페놀성 화합물 함 량과 같이 발효가 진행될수록 유의적으로 증가하는 경향을 나타내었다 $(\mathrm{p}<0.05)$. 미르찰 현미를 이용한 막걸리는 백미 막걸리보다 높은 총페놀성 화합물 함량과 항산화 활성을 나 타냈으며, 이는 추청 현미 막걸리가 백미 막걸리보다 총페놀 화합물 함량과 DPPH 및 $\mathrm{ABTS}$ 라디칼 소거활성이 높다는 결 과와 비교했을 때 본 연구와 유사한 결과를 나타내었다(Kong 등, 2009). 또한, 현미는 총페놀성 화합물의 $80-90 \%$ 가 결합 
(A)

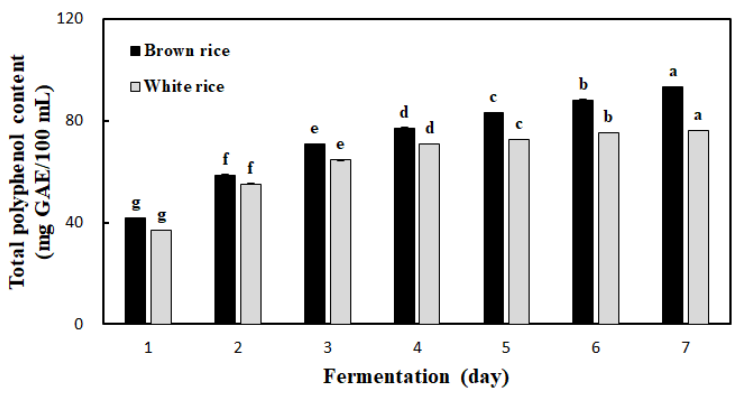

(B)

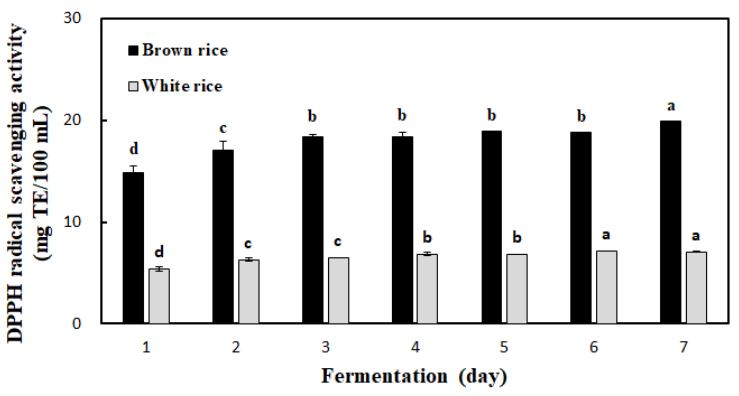

(C)

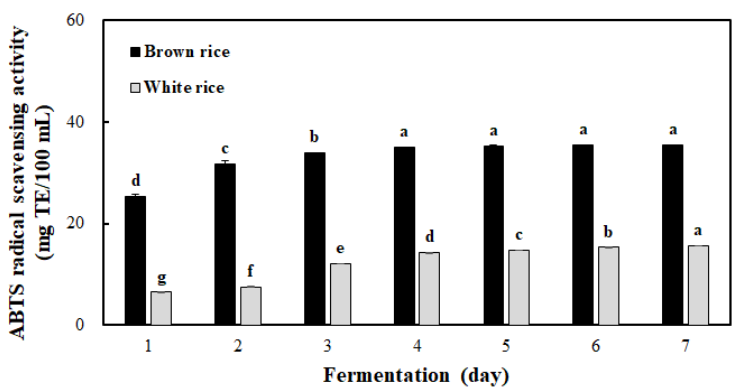

Fig. 2. Antioxidant capacities (total polyphenol content (A), DPPH (B) and ABTS (C) radical scavenging activities) of 'Makgeolli' made using brown and white rice of 'Mirchal'.

Values represent the mean $\pm \mathrm{SD}(\mathrm{n}=3)$. Means with different letters ${ }^{(\mathrm{a}-\mathrm{g}}$ ) above a bar are significantly different at $\mathrm{p}<0.05$.

형(insoluble bound phenolic acid) 페놀산인 반면, 백미는 $53-74 \%$ 로 보고되어 총페놀성 화합물의 구성에도 차이가 있 으며(Kim 등, 2004), 현미를 이용하여 발효를 하였을 때 생 리활성 물질인 $\gamma$-aminobutyric acid(GABA)가 유의적으로 높 아지고, DPPH 및 ABTS 라디칼 소거활성 등 항산화 활성이 높다고 보고된 바 있다(Chung 등, 2015).

\section{주성분 분석}

미르찰 현미와 백미 막걸리의 품질 특성을 측정 변수로 설 정하고 주성분 분석을 하여 그 결과를 Fig. 3(A)에 나타내었 다. 주성분 분석 결과, 제 1 주성분은 $72.56 \%$ 였고, 제 2 주성분 은 $15.48 \%$ 로 설명할 수 있으며, 제 2 주성분까지 누적기여율 은 $88.04 \%$ 로 전체 결과를 설명할 수 있다(Abdi과 Williams,
2010). Fig. 3(A)에서 미르찰 현미 막걸리는 제 1 주성분의 음 의 값 -4 에서 0 까지의 영역에서 그룹을 형성하고 있으며, 미 르찰 백미 막걸리는 제 1 주성분의 양의 값 0 에서 6 까지의 영 역에서 분산되어 그룹을 나타냄으로써 미르찰 현미와 백미 막걸리의 품질 특성 차이를 나타내었다. 또한, 미르찰 현미 막걸리는 발효 1 일차에 제 2 주성분의 음의 값 -4 부근에서 그룹을 형성하고 있으나, 발효 2 일차부터 7 일까지는 제 2 주 성분 0 의 값 부근에서 밀집된 그룹을 형성하고 있는 것을 확 인할 수 있었다. 미르찰 백미 막걸리는 발효 1 일차에 제 2 주 성분의 음의 값 -2 부근에서 그룹을 형성하고 있었으나, 발효 2 일차는 제 2 주성분의 값 0 부근에서, 3 일차부터 7 일까지는 제 2 주성분의 값 1 과 2 부근에 그룹을 나타냄으로써 발효 기 간에 따른 차이를 나타내었다(Seong과 Chung, 2020). 요인 분석은 측정 변수들 간의 상호 연관성을 분석해서 변수들 간 에 공통적으로 작용하고 있는 핵심적인 내재요인으로 축약하 여 나타내는 방법으로 Fig. 3(B)에 나타내었다. 상관관계가 높은 측정변수들의 관계는 3 개의 그룹으로 나타났으며, 첫 번째 그룹은 raffinose, maltose, 총 유리당 함량, 가용성 고형 분 함량, 환원당 함량, 당도 및 glucose로 제 1 주성분의 양의 값에서 분포되어 그룹을 나타냈으며, 두 번째 그룹은 $\mathrm{ABTS}$, $\mathrm{DPPH}, \mathrm{pH}$ 및 $\mathrm{G} / \mathrm{T}$ 로 제 1 주성분의 음의 값에 분포되어 그

(A)

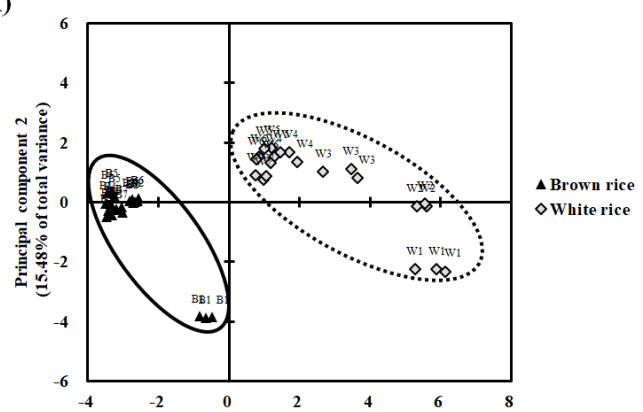

(B)

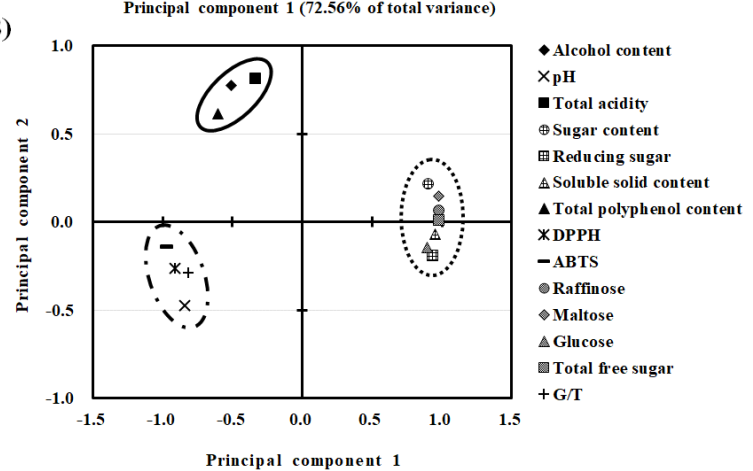

Fig. 3. (A) Score and (B) loading plots of principal component analysis of quality characteristics of 'Makgeolli' made using brown and white rice of 'Mirchal'. 
룹을 나타내었다. 세 번째 그룹은 총산, 알코올 함량 및 총 페놀성 화합물 함량으로 제 2 주성분의 양의 값에서 나타났 다(Seong 등, 2016). 이러한 결과에 따라 미르찰 현미와 백미 막걸리의 품질 특성 차이는 유리당 함량의 영향을 가장 많이 받는 것으로 나타났으며, 발효기간에 따른 품질 특성 차이는 총산, 알코올 함량 및 총페놀성 화합물 함량의 영향을 받는 것으로 사료된다.

\section{요 약}

본 연구에서는 미르찰 현미와 백미 막걸리의 품질 특성을 비교하기 위해 미르찰 현미 및 백미를 7일간 발효시켜 이화 학적 분석을 진행하였고, 그 결과를 측정변수로 주성분 분석 을 하여 미르찰 현미와 백미 막걸리의 발효기간에 따른 품질 특성을 확인하였다. 발효 2 일차부터 미르찰 현미 막걸리는 알코올 함량 $7.00 \%$ 로 백미 막걸리 $3.60 \%$ 보다 높은 알코올 수율을 보였다. 발효가 진행될수록 총페놀성 화합물 함량(현미 막걸리, 42.00-93.37 mg GAE/100 mL; 백미 막걸리, 36.97$76.08 \mathrm{mg} \mathrm{GAE} / 100 \mathrm{~mL}$ ), $\mathrm{DPPH}$ (현미 막걸리, 14.91-19.95 $\mathrm{mg} \mathrm{TE} / 100 \mathrm{~mL}$; 백미 막걸리, 5.37-7.15 mg TE/100 mL) 및 ABTS 라디칼 소거능(현미 막걸리, 25.41-35.54 mg TE/100 $\mathrm{mL}$; 백미 막걸리, $6.49-15.60 \mathrm{mg} \mathrm{TE} / 100 \mathrm{~mL}$ )과 같은 항산화 능이 증가하는 것을 보였으며 $(\mathrm{p}<0.05)$, 그 중 미르찰 현미 막 걸리가 높은 값을 보였다. 또한, 미르찰 현미와 백미 막걸리 의 총 유리당 중 glucose의 비율을 확인한 결과, 현미 막걸리 에서 전체 유리당 중 glucose 함량이 0.88 로, 백미 막걸리 0.60 보다 높은 것을 확인하였다. 반면, 가용성 고형분 함량 (현미 막걸리, 9.20-14.33\%; 백미 막걸리, 17.46-29.75\%), 당 도(현미 막걸리, $11.80-17.40{ }^{\circ} \mathrm{Brix}$; 백미 막걸리, 20.40-28.23 ${ }^{\circ} \mathrm{Brix}$ ), 환원당(현미 막걸리, $4,369-8,859 \mathrm{mg} / 100 \mathrm{~mL}$; 백미 막걸리, 8,275-16,064 mg/100 mL) 및 총 유리당 함량(현미 막 걸리, $475.7-1,080.7 \mathrm{mg} / 100 \mathrm{~mL}$; 백미 막걸리, 1,427.9-2,590.0 $\mathrm{mg} / 100 \mathrm{~mL}$ ) 분석 결과, 미르찰 백미를 이용한 막걸리가 현 미 막걸리보다 높게 나타났다. 이러한 결과를 바탕으로 주성 분 분석 결과, 제 1 주성분 및 제 2 주성분은 각각 $72.56 \%$ 와 $15.48 \%$ 로 나타났으며, 미르찰 현미와 백미 막걸리의 품질 특 성이 구분되는 것으로 나타났다. 또한, 미르찰 현미와 백미 막걸리의 품질 특성 차이를 나타내는 요인으로는 유리당 함 량으로 나타났으며, 발효기간에 다른 품질 특성 차이는 총산, 알코올 함량 및 총페놀성 화합물 함량의 영향을 많이 받는 것으로 사료된다.

\section{감사의 글}

본 연구는 농촌진흥청 연구사업(과제번호: PJ014279012021)
의 지원에 의해 이루어진 것이며 이에 감사드립니다.

\section{Conflict of interests}

The authors declare no potential conflict of interest.

\section{ORCID}

Gi-Un Seong

https://orcid.org/0000-0002-8812-9671

Ji-Yoon Lee

\section{References}

Abdi H, Williams LJ. Principal component analysis. Wiley Interdiscip Rev Comput Stat, 2, 433-459 (2010)

AOAC. Official Methods of Analysis. 15th ed, Association of Official Analytical Chemists, Washington DC, USA, p 777-784 (1990)

Bae EJ, Park YD, Kim HS, Jeong ST, Choi HS. Characteristic flavor of sterilized Makgeollies brewed with different starters. J East Asian Soc Diet Life, 27, 620-628 (2017)

Bang CM, Moon JK, Kong HS. Characteristics of organic acid of Makgeolli by yeast strains type. Korean J Food Cook Sci, 32, 44-49 (2016)

Blois MS. Antioxidant determinations by the use of a stable free radical. Nature, 181, 1199-1200 (1958)

Chung NH, Jo YH, Gao Y, Gu SY, Jeong YJ, Kwon JH. Comparison of physicochemical properties and antioxidant activities of naturally-fermented commercial rice vinegars produced in Korea, China, and Japan. J Korean Soc Food Sci Nutr, 44, 1799-1805 (2015)

Chung NH, Jo YH, Joe MH, Jeong MH, Jeong YJ, Kwon JH. Rice vinegars of different origins: Discriminative characteristics based on solid-phase microextraction and gas chromatography with mass spectrometry, an electronic nose, electronic tongue and sensory evaluation. J Inst Brew, 123, 159-166 (2017)

Ha J, Wang Y, Jang H, Seog H, Chen X. Determination of E, E-farnesol in Makgeolli (rice wine) using dynamic headspace sampling and stir bar sorptive extraction coupled with gas chromatography-mass spectrometry. Food Chem, 142, 79-86 (2014)

Han EH, Lee TS, Noh BS, Lee DS. Quality characteristics in mash of Takju prepared by using different Nuruk 
during fermentation. Korean J Food Sci Technol, 29, 555-562 (1997)

Kim CW, Kang JE, Jeong ST, Choi HS. Physicochemical properties of non-streilized Makgeolli prepared using different fermentation starters and storage conditions. J East Asian Soc Diet Life, 27, 629-634 (2017)

Kim IH, Park WS, Koo YJ. Comparison of fermentation characteristics of Korean traditional alcoholic beverage with different input step and treatment of rice and nuruk (Korean-style bran koji). J Korean Soc Food Cult, 11, 339-348 (1996)

Kim SH, Baek SW. A study on the consumer preferences and choice attributes of purchasing organic instant rice. Korean J Org Agric, 28, 189-208 (2020)

Kim SR, Ahn JY, Lee HY, Ha TY. Various properties and phenolic acid contents of rices and rice brans with different milling fractions. Korean J Food Sci Technol, 36, 930-936 (2004)

Kong SH, Choi YM, Kim YW, Kim DJ, Lee JS. Antioxidant activity and antioxidant components in methanolic extract from Geumjong rice. J Korean Soc Food Sci Nutr, 38, 807-811 (2009)

Kwak JE, Lee JH, Kim HW, Lee JS, Chun AR, Yoon MR, Oh SK, Chang JK, Kim BK. Quality properties of Makgeolli brewed with fiber-rich rice cultivars. Korean J Food Nutr, 27, 851-858 (2014)

Kwon YH, Lee AR, Kim HR, Kim JH, Ahn BH. Quality properties of Makgeolli brewed with various rice and koji. Korean J Food Sci Technol, 45, 70-76 (2013)

Lee BD, Eun JB. Rice processing in food industry. Food Industry and Nutrition, 13, 1-8 (2008)

Lee DH, Lee YS, Cho CH, Seo JS, Park IT, Kim HD, Lim JW. Brewing and fermenting characteristics of Makgeolli produced from high-yielding rice varieties. Korean J Food Sci Technol, 45, 714-720 (2013)

Lee HJ, Lee IS, Jeong HS. Characteristics of Takju with different varieties of rice and particle size. Culi Sci \& Hos Res; CSHR, 18, 191-205 (2012a)

Lee JS, Lee TS, Noh BS, Park SO. Quality characteristics of mash of Takju prepared by different raw materials. Korean J Food Sci Technol, 28, 330-336 (1996)

Lee SA, Park HD. Effect of ground rice particle size on the brewing of uncooked rice Takju. Korean J Post-Harvest Sci Technol Agri Products, 2, 269-276 (1995)

Lee YJ, Yi HC, Hwang KT, Kim DH, Kim HJ, Jung CM, Choi YH. The qualities of Makgeolli (Korean rice wine) made with different rice cultivars, milling degrees of rice, and nuruks. J Korean Soc Food Sci Nutr, 41, 1785-1791 (2012b)

Oh SW, Lee SM, Park SY, Lee SY, Lee WH, Cho HS, Yeo YS. Rice biotechnology and current development. J Korean Soc Int Agric, 28, 24-36 (2016)

Park CW, Jang SY, Park EJ, Yeo SH, Kim OM, Jeong YJ. Comparison of the quality characteristics of commercial Makgeolli type in South Korea. Korean J Food Preserv, 18, 884-890 (2011)

Re R, Pellegrini N, Proteggente A, Pannala A, Yang M, Rice-Evans C. Antioxidant activity applying an improved ABTS radical cation decolorization assay. Free Radical Bio Med, 26, 1231-1237 (1999)

Seong GU, Chung SK. Marker compound contents and antioxidant capacities of the taproot and lateral root of Danshen (Salvia miltiorrhiza Radix). J Appl Biol Chem, 63, 23-28 (2020)

Seong GU, Hwang IW, Chung SK. Antioxidant capacities and polyphenolics of Chinese cabbage (Brassica rapa $\mathrm{L}$. ssp. pekinensis) leaves. Food Chem, 199, 612-618 (2016)

Singleton VL, Rossi JA. Colorimetry of total phenolics with phosphomolybdic-phosphotungstic acid reagents. Am J Enol Viticult, 16, 144-158 (1965)

Song CS, Ju HM, Kim JM. Effects of isoamyl acetate production in Makgeolli according to fermentation conditions. J Life Sci, 30, 162-168 (2020)

Wang SJ, Lee HJ, Cho JY, Park KH, Moon JH. Isolation and identification of antioxidants from Makgeolli. Korean J Food Sci Technol, 44, 14-20 (2012) 